\title{
Adalimumab and Etanercept in the Treatment of Rheumatoid Arthritis and Spondyloarthropathies: Budget Impact Model of Dose Reduction
}

\author{
Alejandro González Álvarez ${ }^{1, *}$, Manuel Gómez Barrera ${ }^{2}$, Joaquín Borrás Blasco ${ }^{3}$ and \\ Emilio José Giner Serret ${ }^{4}$
}

${ }^{1}$ Pharmacy Department, Hospital Obispo Polanco, Teruel, Spain

${ }^{2}$ GIMACES Research Group, Faculty of Health Sciences, Universidad San Jorge, Villanueva de Gállego, Zaragoza, Spain

${ }^{3}$ Pharmacy Department, Hospital de Sagunto, Valencia, Spain

${ }^{4}$ Rheumatology Department, Hospital Obispo Polanco, Teruel, Spain

\begin{abstract}
Objective: To assess the financial impact of spacing out the administration intervals of adalimumab (ADA) and etanercept (ETN) in the treatment of rheumatoid arthritis (RA) and spondyloarthropathies (SAP) in our work setting.

Materials and method: A budget impact model (BIM) was developed to estimate the financial impact of spacing out the usual administration intervals of ADA $40 \mathrm{mg}$ every 2 weeks and ETN $50 \mathrm{mg}$ weekly (scenario A) to ADA 40 mg every 3 weeks and ETN $50 \mathrm{mg}$ every 2 weeks (scenario B), according to the guidelines and recommendations applied to these studies, specifying the target population, the study perspective, the time frame, and analysing the robustness of the study with a threshold univariate sensitivity analysis.

Results: A total of 71 patients were included in the study. The application of a BIM showed annual savings for ADA and ETN of $€ 19,784$ and $€ 38,271$, respectively. The net cost, that is, the savings this entailed for the time frame considered (2 years), amounted to $€ 116,110$. The sensitivity analysis performed shows that the BIM estimated for the study period was very robust, as the net result in the different scenarios varied very little, remaining negative in the new scenarios.

Conclusions: The BIM developed in the study shows the importance of the role of healthcare professionals in the context of sustainability of the healthcare system, where the model could generate large annual net savings for the different regional healthcare systems.
\end{abstract}

Keywords: Rheumatoid arthritis, Spondyloarthropathies, Budget impact analysis, Adalimumab, Etanercept, Tumour necrosis factor alpha inhibitors.

\section{INTRODUCTION}

Rheumatoid arthritis (RA) is a chronic disease that has a large impact on patient quality of life and generates great financial and social costs. Starting in the initial phases, it affects the daily activities of people who suffer from RA, not only in terms of physical aspects, but also social, psychological and financial aspects. It is a common disease and its prevalence varies little between countries, ranging from 0.5 to $1 \%$ [1].

Moreover, the term spondyloarthropathy (SAP) or spondyloarthritis generically designates diseases such as ankylosing spondylitis (AS) and psoriatic arthritis (PsA), among others [2], the prevalence $(0.1-2.5 \%)$ of which varies according to ethnicity, geographic location and, especially, the frequency of HLA-B27 in the general population [3].

*Address correspondence to this author at the Pharmacy Department, Hospital Obispo Polanco, Teruel, Avenida Ruiz Jarabo s/n 44002 Teruel, Spain; Tel: 630433142; E-mail: agonzalezal@salud.aragon.es

ISSN: 2223-3806 / E-ISSN: 1927-5951/14
The treatment of these conditions involves the use of NSAIDs, traditional disease-modifying antirheumatic drugs (DMARDs) or a combination of these and physical therapy in their initial stages. However, if there is no response to these treatments, there are tumour necrosis factor alpha inhibitors (anti-TNFs), such as adalimumab and etanercept, whose efficacy versus placebo has been widely proven in multiple clinical trials. Adalimumab (ADA) is a fully human monoclonal antibody whose recommended dosage is $40 \mathrm{mg}$ administered everyotherweek [4], while etanercept (ETN) is a $75-\mathrm{kDa}$ TNF receptor-lgG1 fusion protein administered as $50 \mathrm{mg}$ weekly [5].

From a socioeconomic viewpoint, the annual costs deriving from RA in Spain have been estimated to be 2,250 million Euros, the average annual cost per patient being $€ 5,900[6,7]$ For SAP, the total mean cost (including direct and indirect costs) is around $€ 7,920$ per patient per year and $€ 75,000$ in cases with poor prognosis or serious disease [8].

The generalised use of DMARDs, the addition of new biologics on the market, the associated

(c) 2014 Lifescience Global 
comorbidity and work disability deriving from these conditions, together with the analysis of these data, comprise the significant financial impact that this group of diseases has on the National Health System.

Thus, it is very important to understand the financial impact generated by different health problems. This is because the resources available to address healthcare and social expenditure are limited and strategies need to be designed to ensure their efficient use.

Therefore, budgetary impact analysis consists of studying the variation that the introduction of a new healthcare intervention will have on the budget of the entity that is funding it. This alternative may involve a new surgical technique, a new analytical technique or, as in our case, drugs against a disease [9].

The objective of this study is therefore to assess the financial impact of spacing out the administration intervals of ADA and ETN to 3 weeks and 2 weeks, respectively, in the treatment of RA and SAP in our work setting.

\section{MATERIALS AND METHOD}

A budget impact model (BIM) has been developed to estimate the financial impact of spacing out the usual administration intervals of ADA $40 \mathrm{mg}$ every 2 weeks and ETN $50 \mathrm{mg}$ weekly (scenario $\mathrm{A}$ ) in the treatment of conditions such as RA and SAP to ADA $40 \mathrm{mg}$ every 3 weeks and ETN $50 \mathrm{mg}$ every 2 weeks (scenario B).

This model was developed according to the guidelines and recommendations applied to these studies [10, 11], specifying the target population, the study perspective, the time frame, and analysing the robustness of the study with a threshold univariate sensitivity analysis.

\section{Target Population}

The study included patients diagnosed with RA and spondyloarthropathies such as AS or PsA who were seen as outpatients at the Teruel Healthcare Sector Rheumatology Department. Inclusion criteria were: males and females over 18 years of age on active treatment with anti-TNF drugs such as ADA and ETN. Exclusion criteria were: diagnosed autoimmune disorders such as Crohn's disease and ulcerative colitis, treatment change to another anti-TNF drug other than ADA or ETN, administration of abatacept or rituximab, and discontinuation of treatment due to adverse effects with anti-TNF therapy.
The following demographic variables were collected for the patients included in the study: age, gender, primarydiagnosis and years on treatment with anti-TNF therapy. The administration of anti-TNF drug dose regimens in patients who remained in clinical remission, understood as DAS28 values $<2.6$ for RA and peripheral PsA and BASDAl $<4$ for AS, and at no risk of radiological progression in the last year of treatment would be spaced out to ADA $40 \mathrm{mg}$ every 3 weeks and ETN $50 \mathrm{mg}$ every 2 weeks.

\section{Study Perspective and Time Frame}

As this is a BIM, the perspective was chosen by the funding entity, in this case the hospital itself and the Aragon Health Service. Only publically funded healthcare resources were included, that is, direct costs generated by each study arm. Therefore, the following were not included: costs paid for by the patients, work productivity losses or other indirect costs. The time frame considered was 2 years (20112013).

\section{Sensitivity Analysis}

Given that every financial model is associated with a certain degree of uncertainty because of the assumptions made, a threshold univariate sensitivity analysis was performed with the variables which were estimated to have a certain degree of associated uncertainty, varying the values adopted in the baseline scenario within a range of $\pm 50 \%$. The variables used were: cost of treatment with ADA and ETN, percentage of patients on treatment with ADA and percentage of patients on treatment with ETN who are candidates for spacing out their dosage interval.

\section{Description of the Budget Impact Model (BIM)}

Finally, the potential savings observed after modifying the administration interval were calculated. The BIM was calculated for both drugs using the following formula [9]:

Formula 1. BIM model.

BIM ETN $=\left(M_{\mathrm{e} 1} \times\left(\mathrm{N}_{\mathrm{e} 1}-\mathrm{N}_{\mathrm{e} 2}\right)\right)+\left(\mathrm{MC}_{\mathrm{e} 2} \times \mathrm{N}_{\mathrm{e} 2}\right)-\left(\mathrm{MC}_{\mathrm{e} 1} \times \mathrm{N}_{\mathrm{e} 1}\right)$

BIM ADA $=\left(\mathrm{MC}_{\mathrm{a} 2} \times\left(\mathrm{N}_{\mathrm{a} 2}-\mathrm{N}_{\mathrm{a} 3}\right)\right)+\left(\mathrm{MC}_{\mathrm{a} 3} \times \mathrm{N}_{\mathrm{a} 3}\right)-\left(\mathrm{MC}_{\mathrm{a} 2} \times \mathrm{N}_{\mathrm{a} 2}\right)$

where $\mathrm{MC}_{\mathrm{e} 1}$ and $\mathrm{MC}_{\mathrm{a} 2}$ were the mean monthly cost of patients treated with ETN $50 \mathrm{mg}$ weekly or ADA $40 \mathrm{mg}$ every two weeks and $\mathrm{N}_{\mathrm{e} 1}$ and $\mathrm{N}_{\mathrm{a} 2}$ were the number of patients on this dosage regimen. $\mathrm{MC}_{\mathrm{e} 2}, \mathrm{MC}_{\mathrm{a} 3}$ and $\mathrm{N}_{\mathrm{e} 2}$, $\mathrm{N}_{\mathrm{a} 3}$ were the mean monthly costs of patients and the 
Table 1: Demographic Characteristics of Patients Included in the Study

\begin{tabular}{|c|c|c|c|}
\hline $\begin{array}{c}\text { Variable } \\
\text { (units) }\end{array}$ & $\begin{array}{l}\text { Etanercept } \\
\qquad(n=26)\end{array}$ & $\begin{array}{l}\text { Adalimumab } \\
\qquad(n=45)\end{array}$ & p \\
\hline Age (years), (SD) & $60.1(12.9)$ & $55.8(12.7)$ & 0.207 \\
\hline Years on anti-TNF treatment & $4.49(3.6)$ & $2.67(2.4)$ & $0.020^{* a}$ \\
\hline $\begin{array}{c}\text { Diagnosis }(n) \\
\text { RA } \\
\text { PsA } \\
\text { AS }\end{array}$ & $\begin{array}{l}17 \\
3 \\
6\end{array}$ & $\begin{array}{l}15 \\
11 \\
19\end{array}$ & $0.032^{* \mathrm{~b}}$ \\
\hline $\begin{array}{c}\text { Gender }(\%) \\
\text { Female } \\
\text { Male }\end{array}$ & $\begin{array}{l}51.3 \\
21.8\end{array}$ & $\begin{array}{l}48.7 \\
78.2\end{array}$ & $0.012^{*^{b}}$ \\
\hline
\end{tabular}

RA: Rheumatoid arthritis; PsA: Psoriatic Arthritis; AS: Ankylosing Spondylitis; $n$ : number of patients; SD: standard deviation; ${ }^{*}$ statistically significant value. Statistical analysis: ${ }^{\mathrm{a}}$ Mann-Whitney $U$ test, ${ }^{\mathrm{b}} \mathrm{X}$ test; level of significance $\mathrm{p}<0.05$

number of patients who were estimated would adopt the new intervention (ADA $40 \mathrm{mg}$ every 3 weeks, ETN $50 \mathrm{mg}$ every 2 weeks).

Moreover, financial variables by condition included the mean cost per patient and mean monthly cost. The costs of the medications considered are expressed in Euros $(€)$, referring to manufacturers' sale price + VAT (4\%) and the 2012 period. Statistical analysis was performed using the PASW Statistics 18.0 computer program (IBM ${ }^{\circledR}$ SPSS software), setting a threshold of $p=0.05$ to accept or reject the null hypothesis.

\section{RESULTS}

A total of 71 patients were included in the study. Table 1 summarises the demographic characteristics.

In terms of financial variables, the mean monthly cost by disease was $€ 30,329$ for RA, $€ 13,615$ for PsA and $€ 24,262$ for AS. The total cost for the three indications amounted to $€ 68,206$. Table 2 shows the mean monthly cost per patient for ADA and ETN before and after spacing out the administration interval.

The number of patients who met clinical remission criteria and candidates for the application of scenario B were 5 patients in the ADA group and 7 patients in the ETN group. The application of a BIM showed annual savings for ADA and ETN of $€ 19,784$ and $€ 38,271$, respectively. The net cost, that is, the savings this entailed for the time frame considered (2 years), amounted to $€ 116,110$.

Figure 1 shows the total savings in Euros based on the progressive introduction of anti-TNF therapy in the study population. The potential savings correspond to the difference between the results of the current cost of patients on regular dosage regimens and future costs based on progressive introduction of the new intervention.

\section{Sensitivity Analysis}

The sensitivity analysis performed (Figures 2-5) shows that the BIM estimated for the 2011-2013 period is very robust, as the net result in the different scenarios varied very little, remaining negative in the new scenarios. Only Figure 4, for costs of ADA treatment under $€ 600$, shows positive values, in this case not achieving financial savings for the model.

\section{DISCUSSION}

According to studies published to date [12-16], in conducting this study and developing the BIM, it has been assumed that both drugs are therapeutically equal for the treatment of said conditions. Nevertheless, it is clear that this assumption will not be

Table 2: Mean Monthly Cost Per Patient for ADA and ETN in the Scenarios Considered

\begin{tabular}{|c|c|c|}
\hline Drug & Scenario $A^{1}$ & Scenario B $^{2}$ \\
\hline \hline ADA & $€ 989.21$ & $€ 659.47$ \\
\hline ETN & $€ 911.23$ & $€ 455.62$ \\
\hline
\end{tabular}

ADA: adalimumab; ETN: etanercept; ${ }^{1}$ : Regular dosage cost, ADA 40 mg every 2 weeks and ETN 50 mg weekly. ${ }^{2}$ : Alternative dosage cost after spacing out the administration interval, ADA 40 mg every 3 weeks and ETN 50 mg every 2 weeks. 


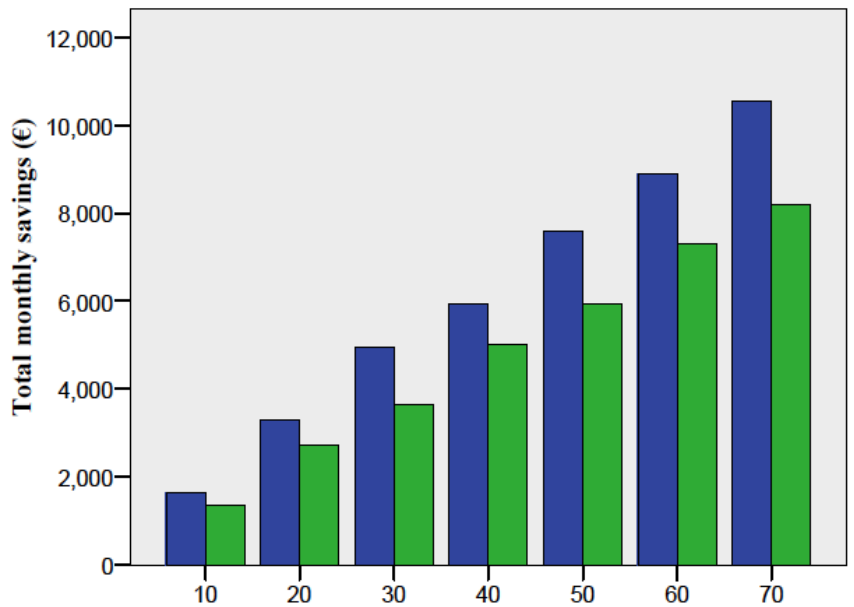

Anti-TNF drug

$\%$ of introduction of anti-TNF therapy (scenario B)

Figure 1: Results of budgetary impact according to perspective.

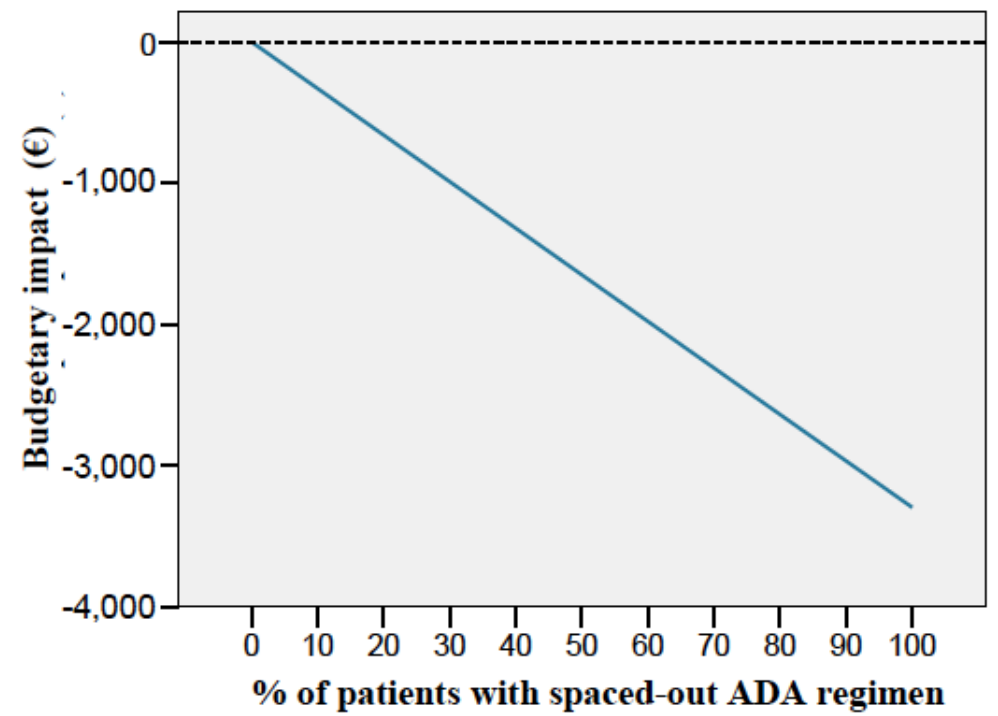

Figure 2: Threshold univariante sensitivity analysis for the percentage of patients with a spaced-out ADA dose regimen.

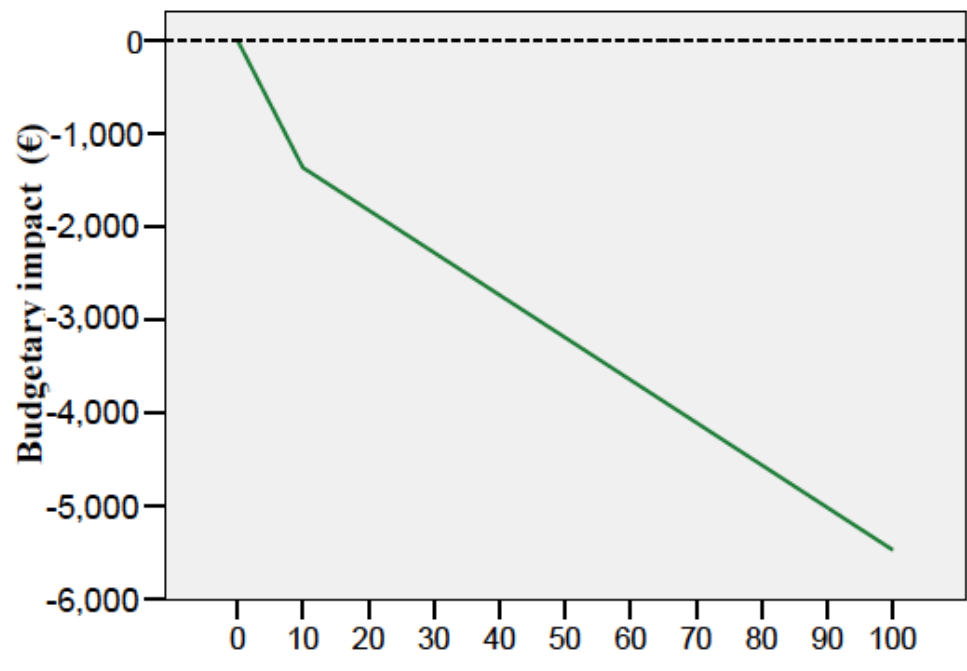

$\%$ of patients with spaced-out ETN regimen

Figure 3: Threshold univariante sensitivity analysis for the percentage of patients with a spaced-out ETN dose regimen. 


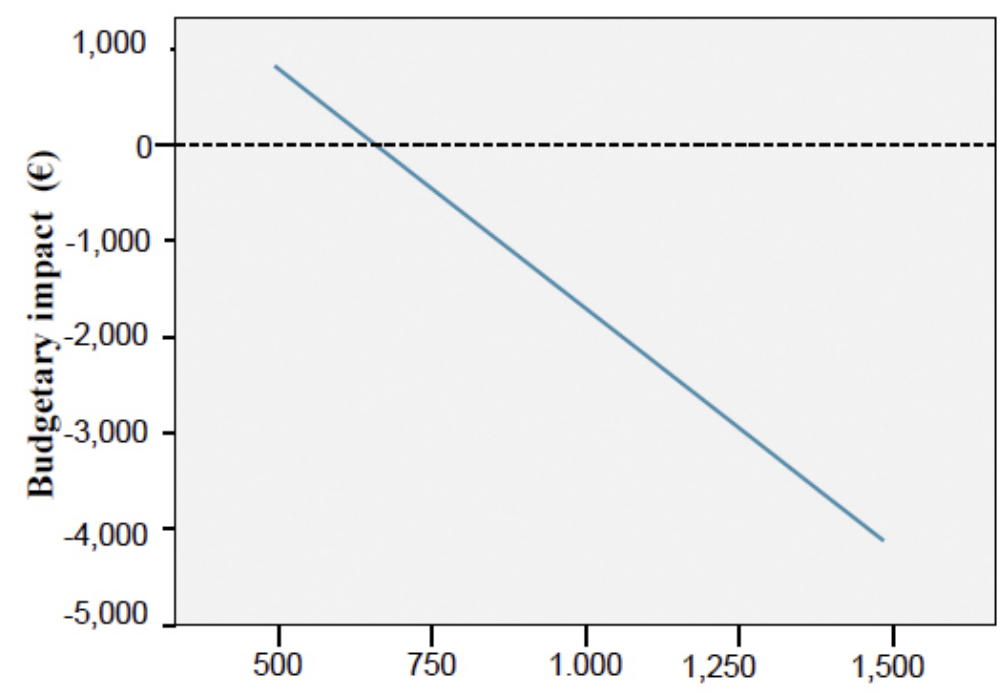

Cost of treatment with ADA(manufactures' sale cost + VAT)

Figure 4: Threshold univariate sensitivity analysis for the cost of treatment with ADA.

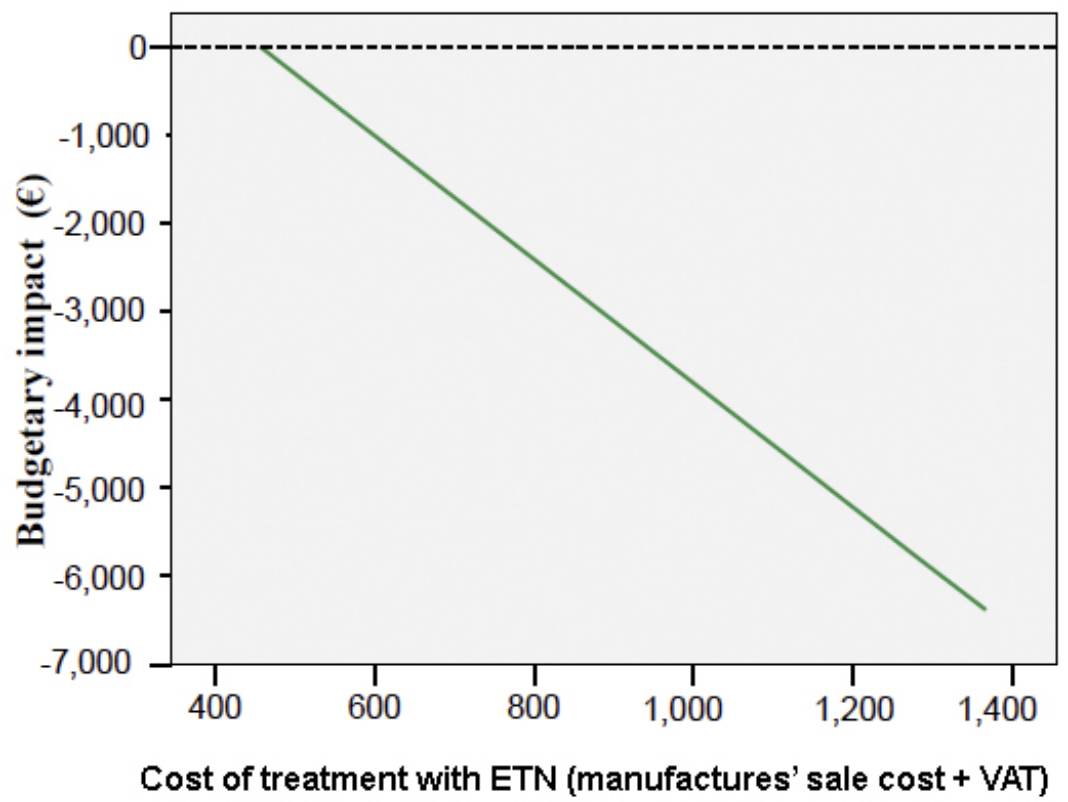

Figure 5: Threshold univariate sensitivity analysis for the cost of treatment with ETN.

completely valid until there are clinical trials that directly compare the two alternatives.

Firstly, analysing the population's demographic variables showed significant differences except in patient age $(p=0.207)$. Gender distribution and average age in the study sample are comparable to those of other studies [17-19], with RA being the most prevalent condition $(p=0.032)$.

Secondly, focusing on the financial perspective, it can be seen that both drugs represent a large part of the hospital's pharmaceutical expenditure, almost $€ 68,000$ per month for the three indications, which leads us to believe that small interventions to control spending in this field may result in significant financial savings.

The BIM designed in this study (formula 1), applying scenario B compared to scenario A, would result in financial savings of $€ 120,000$ in the study period and increase the drug compliance of patients included, which would enable these resources to be reallocated for the treatment of new patients diagnosed with RA or SAP and candidates to receive anti-TNF therapy.

BIM ETN $=\left(\mathrm{MC}_{\mathrm{e} 1} \times\left(\mathrm{N}_{\mathrm{e} 1}-\mathrm{N}_{\mathrm{e} 2}\right)\right)+\left(\mathrm{MC}_{\mathrm{e} 2} \times \mathrm{N}_{\mathrm{e} 2}\right)-\left(\mathrm{MC}_{\mathrm{e} 1} \times \mathrm{N}_{\mathrm{e} 1}\right)$

BIM ADA $=\left(\mathrm{MC}_{\mathrm{a} 2} \times\left(\mathrm{N}_{\mathrm{a} 2}-\mathrm{N}_{\mathrm{a} 3}\right)\right)+\left(\mathrm{MC}_{\mathrm{a} 3} \times \mathrm{N}_{\mathrm{a} 3}\right)-\left(\mathrm{MC}_{\mathrm{a} 2} \times \mathrm{N}_{\mathrm{a} 2}\right)$ 
The increase in this savings is particularly notable as the number of patients who are candidates to adopt the spaced-out dose interval increases. Thus, introducing the spaced-out administration regimen (scenario B) to $70 \%$ of the population could achieve cost reductions of almost $€ 8,000$ and $€ 11,000$ per month for ETN and ADA, respectively (Figure 1). According to the time frame considered (2 years), this would involve savings of between $€ 192,000$ and $€ 264,000$.

With regard to these data, and despite the lack of relevant studies, in our country the PRAXIS [20] study described how substituting ADA for ETN generated a financial impact of between $€ 22,600$ and $€ 362,600$ for a 200-bed hospital, thus showing the importance of focusing on these therapies.

However, given that the healthcare information system is not perfect, the results obtained in the BIM are not without a certain degree of uncertainty in terms of the estimates made. Thus, the sensitivity analysis performed has enabled us to minimize any possible errors and check the model's robustness.

As shown in Figures 2-5, modifying the variables that are subject to uncertainty, such as percentage of patients with the spaced-out regimen and cost of treatment for both ADA and ETN, shows negative values or savings in most cases. Only the particular case of a cost of less than $€ 600$ for ADA was shown to be sensitive to this analysis, not obtaining savings in the model (Figure 4).

This model, like all BIMs, presents certain limitations. These include the limited number of patients included in the study, possibly due our hospital's difficulty in gathering a larger sample, the result of a large dispersion and small population density. Moreover, this is a future projection model on the use of a particular group of medicinal products, based on certain assumptions and the attitude expected of clinicians given the introduction of a new intervention or scenario. Furthermore, we did not collect data on the number of patients who relapse or get worse after modifying the treatment, which would complement the financial data obtained throughout the study.

In conclusion, even given the aforementioned limitations, the BIM developed in this study shows the importance of the role of healthcare professionals in the context of sustainability of the healthcare system, where the model could generate large annual net savings for the different regional healthcare systems. These savings could be increased even more according to the estimation periods and magnitude of patients who are candidates for receiving the new intervention.

\section{CONFLICT OF INTEREST}

The authors declare that they have no conflicts of interest.

\section{REFERENCES}

[1] Griffith J, Carr A. What is the impact of early rheumatoid arthritis on the individual? Best Pract Res Clin Rheumato 2001; 15(1): 77-90.

http://dx.doi.org/10.1053/berh.2000.0127

[2] Khan MA. Update on spondyloarthropathies. Ann Inter Med 2002; 136(12): 896-907. http://dx.doi.org/10.7326/0003-4819-136-12-200206180$\underline{00011}$

[3] Onen F, Akar S, Birlik M, Sari I, Gurler O, Ergor A, et al. Prevalence of ankylosing spondylitis and related spondyloarthritis in an urban area of Izmir, Turkey. Ann Rheumat Dis 2006; 65: 541-2.

[4] Lab. Abbvie Ltd. Summary of product characteristics ofHumira ${ }^{\circledR}$ (adalimumab) [updated 9/2008]. Available at http://www.ema.europa.eu/docs/es ES/document library/EP AR_-_Product_Information/human/000481/WC500050870. pdf

[5] Lab. Pfizer Limited. Summary of product characteristics of Enbrel $\circledast$ (etanercept) [updated 2/2010]. Available at: http://www.ema.europa.eu/docs/es_ES/document_library/EP AR_-_Product_Information/human/000262/WC500027361. pdf

[6] Lajas C, Abasolo L, Bellajdel B, Hernandez-Garcia C, Carmona L, Vargas $\mathrm{E}$, et al. Costs and predictors of costs in rheumatoid arthritis: A prevalence-based study. Arthrit Rheumatism-Arthrit Care Res 2003; 49(1): 64-70. http://dx.doi.org/10.1002/art.10905

[7] Ruiz-Montesinos MD, Hernandez-Cruz B, Ariza-Ariza R Carmona L, Ballina J, Navarro-Sarabia F, et al. Cost analysis in a cohort of rheumatoid arthritis patients managed in rheumatology units in Spain. Reumatol Clin 2005; 1(4): 1939 http://dx.doi.org/10.1016/S1699-258X(05)72744-3

[8] Kobelt G, Sobocki P, Mulero J, Gratacos J, Pocovi A, Collantes-Estevez E. The burden of ankylosing spondylitis in Spain. Value Health 2008; 11(3): 408-15.

http://dx.doi.org/10.1111/j.1524-4733.2007.00252.x

[9] Brosa M, Gisbert R, Rodríguez JM, Soto J. Principios, métodos y aplicaciones del análisis de impacto presupuestario en el sector sanitario. PharmacoeconomicsSpanish Res Articl 2005 (2): 65-78.

[10] Trueman P, Drummond M, Hutton J. Developing guidance for budget impact analysis. Pharmacoeconomics 2001; 19(6): 609-21. http://dx.doi.org/10.2165/00019053-200119060-00001

[11] Orlewska E, Mierzejewski P. Proposal of polish guidelines for conducting financial analysis and their comparison to existing guidance on budget impact in other countries. Value Health $2004 ; 7(1): 1-10$ http://dx.doi.org/10.1111/j.1524-4733.2004.71257.x

[12] Salliot C. Indirect comparisons of the efficacy of biological antirheumatic agents in rheumatoid arthritis in patients with an inadequate response to conventional disease-modifying antirheumatic drugs or to an anti-tumour necrosis factor 
agent: a meta-analysis. Ann Rheumat Dis 2011; 70(3): 660665.

[13] Schmitz S, Adams R, Walsh CD, Barry M, FitzGerald O. A mixed treatment comparison of the efficacy of anti-TNF agents in rheumatoid arthritis for methotrexate nonresponders demonstrates differences between treatments: a Bayesian approach. Ann Rheumat Dis 2012; 71(2): 225-30. http://dx.doi.org/10.1136/annrheumdis-2011-200228

[14] Mandema JW, Salinger DH, Baumgartner SW, Gibbs MA. A Dose-Response Meta-Analysis for Quantifying Relative Efficacy of Biologics in Rheumatoid Arthritis. Clin Pharmacol Therapeut 2011; 90(6): 828-35. http://dx.doi.org/10.1038/clpt.2011.256

[15] Kirchhoff TD, Mittendorf T, Schmidt RE, Jablonka A, Merkesdal S. Cost-effectiveness of TNF-alpha inhibition in active ankylosing spondylitis: a systematic appraisal of the literature. Expert Rev Pharmacoeconomics Outcomes Res 2012; 12(3): 307-17

http://dx.doi.org/10.1586/erp.12.19

[16] Cortesi PA, Scalone L, D'Angiolella L, Belisari A, Fusco F, Olivieri I, et al. Systematic literature review on economic implications and pharmacoeconomic issues of psoriatic arthritis. Clin Exper Rheumatol 2012; 30(4 Suppl 73): 126-31.
[17] Carter CT, Changolkar AK, Scott McKenzie R. Adalimumab, etanercept, and infliximab utilization patterns and drug costs among rheumatoid arthritis patients. J Med Econom 2012; 15(2): 332-9.

http://dx.doi.org/10.3111/13696998.2011.649325

[18] Bullano MF, McNeeley BJ, Yu YF, Quimbo R, Burawski LP $\mathrm{Yu} E \mathrm{~B}$, et al. Comparison of costs associated with the use of etanercept, infliximab, and adalimumab for the treatment of rheumatoid arthritis. Managed Care Interf 2006; 19(9): 47-53.

[19] Wu E, Chen L, Birnbaum H, Yang E, Cifaldi M. Cost of care for patients with rheumatoid arthritis receiving TNFantagonist therapy using claims data. Curr Med Res Opin 2007; 23(8): 1749-59.

http://dx.doi.org/10.1185/030079907X210615

[20] Rubio-Terres C, Ordovas Baines JP, Pla Poblador R, Martinez Nieto C, Sanchez Garre MJ, Rosado Souviron MA, et al. [Use and cost of biological disease-modifying antirheumatic drugs in Spain (PRAXIS study)]. Farmaciahospitalaria: organooficial de expresion cientifica de la Sociedad Espanola de Farmacia Hospitalaria 2007; 31(2): 78-92. 